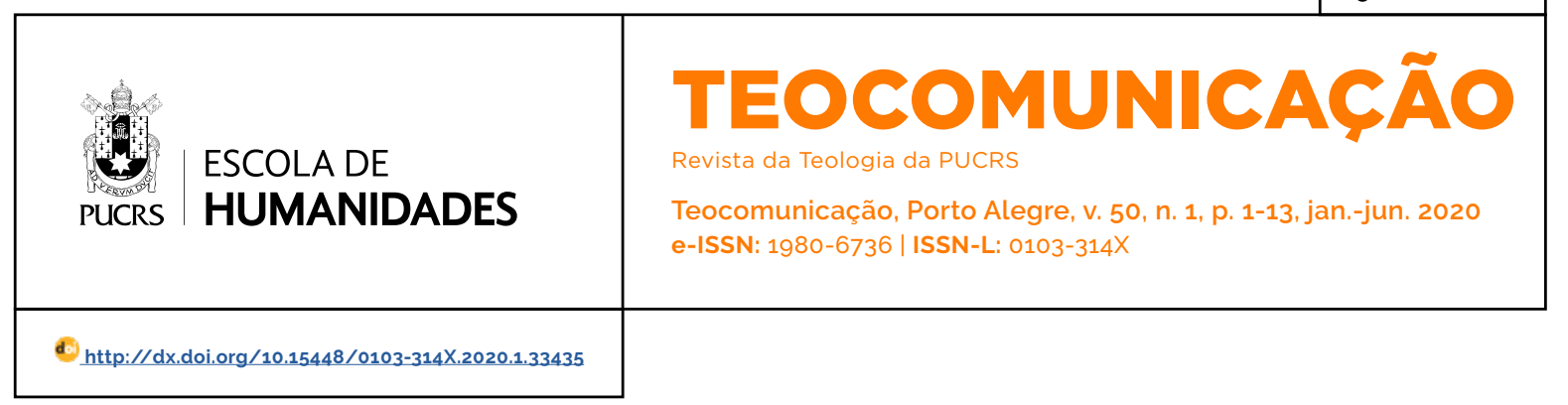

SEÇÃO: ARTIGOS

\title{
A declaração Dignitatis Humanae e o entendimento de John Finnis sobre a liberdade religiosa
}

\author{
Dignitatis Humanae and John Finnis's understanding of religious freedom
}

\section{Laura Souza Pires do Rio ${ }^{1}$ \\ orcid.org/00000002-2086-6907 \\ laurapiresdorio@gmail.com}

Recebido em: 25/2/2019.

Aprovado em: 4/6/2020.

Publicado em: 05/11/2020.

\begin{abstract}
Resumo: Este artigo pretende incentivar o leitor a aprofundar sua compreensão acerca dos elementos da Lei natural presentes no pensamento de John Finnis, principalmente no que concerne ao direito humano da liberdade religiosa. Isso se deve ao fato desse autor apresentar uma perspectiva única sobre a religião, de maneira a considerá-la como um dos bens humanos fundamentais básicos. Antes de ser um direito humano protegido em tratados internacionais e nas Constituições de diversos paises, a religião, de acordo com sua teoria, é um bem humano que deve ser protegido. Tal proteção é imprescindivel para o cumprimento de todas as potencialidades de cada ser humano, para que seja possivel atingir o seu florescimento humano e, assim também, o bem comum. Dessa forma, será discutido neste trabalho se a liberdade religiosa, sob a ótica de John Finnis, é universal e se deveria, assim, ser endossada e aplicada universalmente em todo o mundo, utilizando como exemplo, o documento do Concilio do Vaticano II - Dignitatis Humanae (1965). Ainda, será realizada uma análise bibliográfica das obras desse autor que versam sobre esse tema a fim de identificar quais são, e se existem, princípios da liberdade religiosa que são universalmente aplicáveis no mundo inteiro e, principalmente, no Ocidente. Dessa forma, a partir da identificação desses principios será reconhecida a relevância da proteção e do incentivo ao exercício desse direito no espaço público, diante do caráter natural relativo ao bem humano da religião, tendo em vista a teoria apresentada por John Finnis.
\end{abstract}

Palavras-chave: Lei natural. Direito humano. Liberdade religiosa.

Abstract: This paper aims to encourage the reader to deepen his understanding of the elements of natural law inserted in the thought of John Finnis, especially in what concerns the human right of religious freedom. This is due to the fact that this author presents a unique perspective on religion, in order to consider it as one of the fundamental basic human goods. Before being a human right protected in international treaties and in the Constitutions of various countries, religion, according to its theory, is a human good that must be protected. Such protection is essential for the fulfillment of all the potentialities of each human being, so that it is possible to reach its human flourishing and, thus, the common good. Thus, it will be discussed in this paper whether religious freedom, from the perspective of John Finnis, is universal and should thus be endorsed and universally applied throughout the world, using as an example the document of the II Vatican Council - Dignitatis Humanae (1965). Also, a bibliographical analysis of the author's works on this topic will be carried out in order to identify what are, and if they exist, principles of religious freedom that are universally applicable throughout the world and especially in the West. Thus, the identification of these principles will be recognized the relevance of protection and encouragement to the exercise of this right in the public space, given the natural character relative to the human good of religion, in view of the theory presented by John Finnis. Keywords: Natural Law. Religious freedom. Human Rights. 


\section{Introdução}

A Constituição da República Federativa do Brasil de 1988, hoje em vigor, em seu Título II (Dos Direitos e Garantias Fundamentais), determinou o seguinte:

Art. $5^{\circ}$ Todos são iguais perante a lei, sem distinção de qualquer natureza, garantindo-se aos brasileiros e aos estrangeiros residentes no País a inviolabilidade do direito à vida, à liberdade, à igualdade, à segurança e à propriedade, nos termos seguintes:

\section{[...]}

VI - é inviolável a liberdade de consciência e de crença, sendo assegurado o livre exercício dos cultos religiosos e garantida, na forma da lei, a proteção aos locais de culto e a suas liturgias;

VII - é assegurada, nos termos da lei, a prestação de assistência religiosa nas entidades civis e militares de internação coletiva;

VIII - ninguém será privado de direitos por motivo de crença religiosa ou de convicção filosófica ou politica, salvo se as invocar para eximir-se de obrigação legal a todos imposta e recusar-se a cumprir prestação alternativa, fixada em lei (BRASIL, [1988]).

Vislumbra-se que o Estado brasileiro considera, portanto, fundamental a proteção à liberdade religiosa, de maneira que ela é inserida no rol dos direitos e das garantias constitucionais fundamentais a todo ser humano, brasileiro ou estrangeiro. Essa proteção é, ainda, consolidada em diversos tratados internacionais, dentre eles a Declaração Universal dos Direitos Humanos da Organização das Nações Unidas (ONU) (1948). No que concerne à Declaração Universal dos Direitos Humanos, 0 direito à liberdade religiosa é previsto no artigo 18:

Todo ser humano tem direito à liberdade de pensamento, consciência e religião; este direito inclui a liberdade de mudar de religião ou crença e a liberdade de manifestar essa religião ou crença, pelo ensino, pela prática, pelo culto e pela observância, em público ou em particular (ONU, 2009). ${ }^{2}$

Ainda, referente a essa Declaração, no item 2, do seu artigo 26, a Organização das Nações
Unidas dispôs acerca do direcionamento da educação ao integral desenvolvimento da personalidade humana e ao fortalecimento do respeito pelos direitos humanos e liberdades fundamentais. De maneira que a educação deve visar à promoção da compreensão, da tolerância e da amizade entre todas as nações, grupos raciais ou religiosos, tendo como fim a manutenção da paz. ${ }^{3}$

Dessa forma, a liberdade religiosa é considerada não apenas no território brasileiro, mas em âmbito internacional, uma liberdade fundamental de todo ser humano. Importante ressaltar que há um sistema global de proteção dos direitos humanos, composto por tratados internacionais abertos à adesão de todos os Estados, indistintamente de sua localização geográfica, e de órgãos voltados a promover a dignidade humana em todo o mundo (PORTELA, 2014, p. 853).

Contudo, o conceito de direitos humanos é sujeito a discussões controversas, uma vez que existem diversos entendimentos do que realmente constituem esses direitos. Isso ocorre devido às variadas e seculares reflexões filosóficas que se desenvolveram em culturas das mais variadas. Nesse sentido, John Finnis, ao buscar desenvolver uma Nova Teoria do Direito Natural, como é denominada por alguns autores, tais como Pinheiro e Souza (2016a, p. 2), ampliou o conhecimento do campo jurídico-filosófico-político acerca da conceituação dos direitos humanos.

Contudo, não iremos focar o estudo aprofundado de John Finnis sobre essa conceituação, uma vez que se trata de uma análise extensa sobre os conceitos dos próprios termos direitos humanos e, assim, ultrapassaria o objetivo deste artigo. Iremos nos ater, contudo, a analisar o pensamento desse autor acerca da religião como bem humano básico, direito humano, e a universalidade a ela inerente. Universalidade essa que é, de acordo com Finnis, atribuida a todo ser humano como tal e, que necessita ser compreendida como um dos

\footnotetext{
2 O texto da versão portuguesa no site da própria ONU apresenta uma variante significativa em relação à tradução para o Brasil. Trata-se da tradução de belief. O termo é traduzido na versão do site da própria ONU por convicção. Em várias outras línguas, essa é uma opção consequente. De acordo com Bielefeldt (2012, p. 20) o uso do termo belief visa explicitamente proteger convicções não religiosas como o agnosticismo, o ateismo e outros.

3 Diz o trecho: "2. A instrução será orientada no sentido do pleno desenvolvimento da personalidade humana e do fortalecimento do respeito pelos direitos humanos e pelas liberdades fundamentais. A instrução promoverá a compreensão, a tolerância e a amizade entre todas as nações e grupos raciais ou religiosos, e coadjuvará as atividades das Nações Unidas em prol da manutenção da paz" (ONU, 2009, Art. XXVI, 2).
} 
principios fundamentais da liberdade religiosa como direito humano que é.

Diante disso, todavia, para que seja possivel inserir a compreensão da liberdade religiosa como direito humano, a ser universalmente endossado e aplicado, será preciso apresentarmos a noção geral que existe no campo internacional acerca desses direitos. Será, portanto, considerado o estudo realizado por Paulo Henrique Gonçalves Portela, o qual será de grande auxilio para a primeira análise desses direitos. Segundo Portela,

definimos os direitos humanos como aqueles direitos essenciais para que o ser humano seja tratado com a dignidade que the é inerente e aos quais fazem jus todos os membros da espécie humana, sem distinção de qualquer espécie. Os direitos humanos configuram defesa contra os excessos de poder; tanto o estatal como aquele exercido por entes privados, sejam pessoas naturais ou juridicas. Entretanto, consistem também em pauta voltada a orientar as politicas públicas e as ações privadas. É nesse sentido que não mais deve persistir o entendimento tradicional, pelo qual apenas o Estado seria obrigado a promover e proteger os direitos humanos (PORTELA, 2014, p. 817).

Ainda, no primeiro item deste artigo, será apresentada uma breve visão sobre o entendimento dos direitos humanos, apenas com o intuito de inserir o leitor na linha de pensamento de John Finnis sobre a liberdade religiosa. Não iremos, portanto, nos aprofundar neste estudo no presente artigo.

O desenvolvimento do entendimento dos direitos humanos se deu, principalmente, devido ao fato de que a sua compreensão deriva da racionalidade inerente ao ser humano que pode ser identificada na história da humanidade. Em outras palavras, foi a própria capacidade da pessoa humana de raciocinar que possibilitou a classificação desses direitos como essencialmente humanos e dignos de proteção.

De fato, parte importante dos povos da Antiguidade já definia normas relativas à proteção de valores vistos como essenciais para a vida humana. O Código de Hamurábi (1690 a. C.), por exemplo, consagrava a todos os individuos direitos como a vida, a propriedade e a honra. O povo judeu, referência importante para a formação do mundo ocidental, definia nos Dez Mandamentos normas relativas à proteção da vida ('Não matarás'), ao direito de propriedade ('Não roubarás'), à proteção da familia ('Não cometerás adultério') e da honra ('Não darás falso testemunho') (PORTELA, 2014, p. 824

Portanto, diante disso, pode-se perceber que essa capacidade de raciocinar, no sentido de visar à proteção de valores essenciais à vida humana, identificada em todos os seres humanos na história, em si também consiste em um valor essencial para a vida humana. John Finnis, perante tal constatação, denomina esse valor de "conhecimento", e em sua obra Lei Natural e Direitos Naturais dedica um capítulo inteiro para abordá-lo.

Sobre esse valor, John Finnis o identifica em sua obra principal como um dos bens humanos fundamentais básicos por ele apreendidos mediante a realização de uma nova interpretação da teoria do direito natural desenvolvida anteriormente por Tomás de Aquino e Aristóteles. Nesse sentido, são identificados por Finnis setes bens humanos básicos: a) vida; b) conhecimento; c) jogo; d) experiência estética; e) sociabilidade (amizade); f) razoabilidade prática; e g) religião.

Com o intuito de auxiliar o leitor acerca do entendimento sobre esses bens humanos básicos, cabe mencionar a reflexão de Victor Sales Pinheiro e de Elden Borges Souza no que tange aos aspectos característicos desses bens humanos básicos:

\begin{abstract}
Eles são elementos ou aspectos da vida humana que permitem o florescimento da personalidade do homem - todo e qualquer homem. Isto é, são os elementos que permitem que o ser humano se realize como tal. Para Aristóteles (2001), o homem não nasce pronto, ele é uma potência. Tanto quanto o corpo precisa de alimentos para que possa se desenvolver, tanto quanto é necessário o sono para a ação, a alma humana precisa realizar certos bens que plenificam a natureza humana e realizam a humanidade do homem (SOUZA; PINHEIRO, 2016a, p. 12).
\end{abstract}

Esses autores demonstram que a compreensão de Finnis sobre a racionalidade inerente à pessoa humana consiste exatamente em sua natureza, a qual the confere experiências de beleza, de conhecimento e de questionar metafisicamente a ordem da realidade. Assim, o indivíduo reflete, principalmente, sobre o componente divino dessa realidade, que corresponde ao bem da religião, de acordo com o pensamento de John Finnis (SOUZA; PINHEIRO, 2016a, p. 12). 
A religião, como ordenação racional do ser humano a uma ordem primária de todas as coisas, configura-se sempre, quando devidamente respeitada, em um compromisso com a razão. Consiste na busca racional livre da verdade que possui proteção em diversos tratados internacionais e constituições de vários Estados. Fato esse que será analisado neste artigo sob a ótica do pensamento de John M. Finnis, conforme por ele discutido em debate realizado em novembro de 2011 no Religious Freedom Project (Projeto sobre a Liberdade Religiosa) realizado pela Universidade de Georgetown:

A articulação que apresentei acerca do conteúdo desse direito à liberdade religiosa percorre um caminho próximo ao do Artigo 18 da Declaração Universal dos Direitos Humanos, do Artigo 9 da Convenção Européia de Direitos Humanos, e estreitamente ao da declaração do Concilio Vaticano II sobre liberdade religiosa, Dignitatis Humanae (FINNIS et al.. p. 23, tradução nossa).

Nesse debate sobre a liberdade religiosa, John Finnis apresentou sua compreensão de que a religião, como bem humano básico que é, deve ser protegida, o que pode ser comprovado principalmente diante da sua respectiva positivação. Nos dispositivos legais citados, a liberdade religiosa é considerada como um direito humano, e, por isso, não pode ser ofendida por qualquer forma de coação e violência, mas preservado.

Em um primeiro momento, será analisado o bem humano da religião de acordo com o pensamento de John Finnis e, a necessidade de normatização da liberdade religiosa como direito humano que visa a proteção deste bem. Será realizada uma pesquisa bibliográfica dos artigos do autor sobre este tema, bem como do documento do Concilio do Vaticano II, Dignitatis Humanae, que versa exatamente sobre a liberdade religiosa.

No presente artigo, o leitor é convidado a analisar um documento do Concílio Vaticano II (1962-1965) sob o ponto de vista de John Finnis: a Declaração sobre a liberdade religiosa Dignitatis humanae. Acerca desse documento, serão examinadas as respectivas ponderações de Finnis sobre a relevância desse documento no debate público no que tange a liberdade religiosa.

Em um segundo momento, serão analisados, também, os artigos de Finnis sobre a importância e a universalidade da religião no espaço público. Dessa forma, diante do exposto, será possivel concluir pela pertinência da liberdade religiosa para o florescimento humano e, portanto, bem comum de toda sociedade, quando nos deparamos com a teoria apresentada por esse autor.

\section{A religião como direito humano no pensamento de John Finnis}

De maneira a visar uma melhor compreensão do que consistem os direitos humanos, será necessário para o presente estudo apresentar brevemente a classificação tradicional acerca das gerações desses direitos. Usa-se o termo "gerações" devido à existência da relevância atribuída a determinados direitos em cada etapa histórica, de maneira que em periodos específicos, alguns valores foram elevados à classificação de direitos humanos dignos de proteção. Atualmente, a doutrina positivista majoritária utiliza a denominação de "dimensões" ao invés de "gerações", contudo, a compreensão permanece a mesma (SOUZA; PINHEIRO, 2016a, p. 12).

\begin{abstract}
A classificação dos direitos humanos em gerações é sintetizada pela jurisprudência do STF, nos seguintes termos: 'enquanto os direitos de primeira geração (direitos civis e políticos) - que compreendem as liberdades clássicas. negativas ou formais - realçam o principio da liberdade, e os direitos de segunda geração (direitos econômicos, sociais e culturais) - que se identificam com as liberdades positivas, reais ou concretas - acentuam o princípio da igualdade, os direitos de terceira geração, que materializam poderes de titularidade coletiva atribuidos genericamente a todas as formações sociais, consagram o princípio da solidariedade e constituem um momento importante no processo de desenvolvimento, expansão e reconhecimento dos direitos humanos, caracterizados enquanto valores fundamentais indisponiveis, pela nota de uma essencial inexauribilidade' (PORTELA, 2014, p. 828).
\end{abstract}

A fim de contextualizar esse debate é preciso reconhecer que após as atrocidades praticadas nas duas grandes guerras mundiais, principalmente diante do genocidio executado pelo Estado

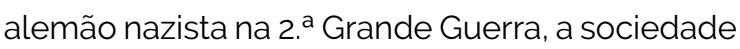
internacional retomou sua atenção para a pertinente necessidade de normatização em âmbito internacional desses direitos. Para tanto, foi criada em 1945 a Organização das Nações Unidas (ONU) para dirimir tais assuntos internacionalmente. Em 
1948, mediante a elaboração da Resolução da Assembleia Geral, foi proclamada pela ONU a Declaração Universal dos Direitos Humanos, a qual é reconhecida como uma das principais referências relativas aos direitos humanos mundialmente.

Isso ocorre, pois suas normas foram normatizadas nas constituições de diversos Estados, fortalecendo assim a eficácia de seu conteúdo no Direito interno desses. Conforme Portela:

Do ponto de vista técnico-formal, a Declaração é uma mera resolução da Assembleia Geral das Nações Unidas, com caráter de recomendação, juridicamente não-vinculante. Com isso, os preceitos contidos na Declaração não seriam, em principio, obrigatórios, ao menos à luz de um entendimento calcado em noções mais antigas do Direito, de caráter mais formalistas e menos ligadas a valores, dentro das quais, a propósito, a proteção da dignidade humana não tinha o destaque de que hoje se reveste. Entretanto, na atualidade, é majoritário o entendimento de que os dispositivos consagrados na Declaração são juridicamente vinculantes, visto que os preceitos contidos em seu texto já foram positivados em tratados posteriores e no Direito interno de muitos Estados (PORTELA, 2014, p. 855-856).

Essa assertiva encontra sua concretização na leitura do artigo 18 da Declaração Universal dos Direitos Humanos, já citado concomitantemente com a própria Constituição Brasileira de 1988, em seus artigos $1^{\circ}$ ao $5^{\circ}$, mencionados, uma vez que se verifica a positivação dos direitos humanos na esfera do; território brasileiro. Dessa forma, nas palavras de Portela:

A Declaração é o ponto de partida da construção do atual sistema internacional de proteção aos direitos humanos. Nesse sentido, suas normas são percebidas como o parâmetro mínimo de proteção da dignidade humana, a ser observado por todos os povos do mundo e efetivado por indivíduos e entidades públicas e privadas, internacionais e nacionais (PORTELA, 2014, p. 856).

Entretanto, será analisado exclusivamente, no presente artigo, o tema do direito humano relativo ao bem humano da religião, previsto no Artigo 18 dessa Declaração, no que concerne à universalidade da liberdade religiosa reconhecida tanto neste e demais dispositivos, quanto por John Finnis.
Essa análise será realizada sob a ótica do entendimento do filósofo e jurista John Finnis. Isso porque, esse autor expôs para a academia jurídica mundial uma compreensão única e inovadora acerca da religião, pois a considera como um bem humano fundamental básico. Por ser assim compreendida, a religião deverá ser protegida e fomentada, para que seja alcançado o florescimento humano de cada pessoa.

No artigo de sua autoria, "Religion and Public Life in Pluralist Society" (2011), John Finnis introduz a compreensão de que é possivel admitir a existência de bens humanos fundamentais básicos capazes de propiciar o florescimento humano. ${ }^{4}$ $E$, isso é possivel sem, contudo, fazer qualquer menção a uma causalidade ou vontade divina. Esse entendimento também se aplica ao próprio bem humano da religião, uma vez que a ordenação do indivíduo ao transcendente é um ato racional direcionado para a busca da verdade sobre a ordem da realidade, conforme se pode ver a seguir:

A identificação dos aspectos básicos do florescimento humano pode ser feita e defendida contra objeções e mal-entendidos, sem apelar para qualquer ideia de causalidade divina, menos ainda para qualquer ideia de uma vontade divina sobre o que devemos e não devemos escolher. A investigação sobre o florescimento humano pode prosseguir sem advertir para a questão da existência divina; o bem de se relacionar apropriadamente com uma fonte transcendente e inteligente de tudo o que conhecemos pode ser postulado sem ser afirmado - pode ser deixado, isto é, como uma espécie de espaço no relato do florescimento humano, a ser ocupado pelo bem que chamamos religião se, mas apenas se, mais investigações mostrarem que tal ser deve ser julgado como existente. Assim, quando se busca (a) a investigação dos principios da compreensão prática que nos direcionam para os aspectos básicos do florescimento humano. e (b) a investigação da exigência racional de que permaneçamos abertos em todas as deliberações e escolhas da diretividade de cada um desses primeiros princípios, e da mesma forma (c) a investigação sobre as implicações desse requisito, implicações que chamamos de moralidade, pode-se proceder, como se faz nas ciências naturais, sem advertir para a seguinte questão: a questão de saber se o fato de que todos esses principios são verdadeiros e o fato de termos a capacidade de reconhecê-los e

4 Sobre florescimento humano, Finnis compreende que o ser humano, em circunstâncias especificas, é capaz de florescer, no sentido de alcançar toda a sua potencialidade, toda a sua realização. Contudo, o florescimento não ocorre para todas as pessoas de maneira idêntica, uma vez que a liberdade racionalmente inerente a cada ser humano permite a sua respectiva aderência a planos de vidas distintos e exclusivos a cada um. Esses planos de vida serão determinados tendo em vista as diversas escolhas, decisões de cada pessoa (SOUZA; PINHEIRO, 2016b, p. 81). 
moldar a nós mesmos e o mundo de acordo, não são fatos que só podem ser explicados como efeitos de uma causalidade que, por razão de ser, causa esses fatos, e não precisa de mais explicações. Essa 'questão adicional' poderia ser adiada até o fim, ou pelo menos até o fim dos meus livros NLNR [Natural Law and Natural Rights] e FoE [Fundamentals of Ethics] ; Obviamente, se a resposta for positiva, as implicações precisam ser consideradas e receber a devida importância, no devido tempo (FINNIS, 2011b, p. 42, tradução nossa).

John Finnis entende que, ao fazer uso da razão, é possivel a todo ser humano identificar objetivamente os aspectos básicos do florescimento humano, sem mencionar qualquer causalidade ou vontade divina. Nesse sentido, os seres humanos em si possuem potencialidades, aspectos básicos que os permitem alcançar o cumprimento de seu florescimento humano. Assim, a identificação dessas potencialidades não necessita de qualquer alusão à vontade divina do ser transcendente inteligente em relação ao qual se busca uma harmonia. Contudo, é preciso reconhecer a existência desse ser transcendente para que seja possivel considerar a religião como bem humano básico. Pois a religião, entendida como um bem enquanto relação adequada com uma fonte transcendente e inteligente de tudo que é possivel conhecer, somente pode ser assim identificada se essa fonte for considerada existente.

Diante dessa constatação, o autor passa a ponderar em suas obras, no que tange a esse tema, acerca da existência da fonte transcendental, que Tomás de Aquino chamava de Deus, e Aristóteles denominava de primeiro motor. Essa investigação se deu a fim de esclarecer a natureza de bem humano fundamental básico atribuída à religião que, nas palavras de Finnis, somente poderia ser postulado caso o ser transcendental fosse tido como existente.

Afinal, o capitulo XIII do meu NLNR INatural Law and Natural Rights] está bem ali nas mãos de todo leitor do livro, com o seguinte argumento, perseguido através de algumas páginas, de que a 'outra questão' acerca da origem de tudo que nós viemos a reconhecer apenas pode ser respondida razoavelmente por julgar que - para colocar o tema tão brevemente quanto possivel - a existência de Deus e a inteligente e necessariamente livre escolha de criar é a explicação necessária (FINNIS, 2011b, p. 43, tradução nossa).

Nesse sentido, por entender que a origem de tudo somente poderia existir mediante a livre e inteligente escolha de um ser que tudo criou, o autor argumenta sobre a relevância da religião para a plena realização do ser humano. Isso se justifica uma vez que, ao se deparar com um mundo inteligentemente ordenado, Finnis, assim como Tomás de Aquino e Aristóteles, não se permite ser indiferente a essa ordem natural de todas as coisas. Dessa maneira, Finnis compreende que, diante de um mundo ordenado e sustentado de forma claramente inteligente, há, em relação a este universo, um ato inteligente que o criou, ato esse livre de toda potencialidade, sendo em si apenas ato. Ou seja, é o primeiro ato, o primeiro motor estudado por Aristóteles em sua obra Metafísica.

\begin{abstract}
A causa, ordenação e sustentação do universo deve, portanto, ser um ato intelectual o qual em um único e mesmo ato atemporal tanto projeta (mediante o entendimento prático), quanto efetiva (por vontade), em cada detalhe, este mundo com todos os seus sistemas causais e explicativos, suas galáxias inimagináveis, partículas subatômicas, e forças fundamentais - um mundo, também, de genomas, células, e cérebros; de matemática, e lógica o qual (mesmo sem aspirar a) se encaixam nesse mundo; de lealdade, justiça, e remorso; de computadores, sinfonias, xadrez e constituições (FINNIS,1998, p. 305, tradução nossa).
\end{abstract}

Enquanto realidade do ato inteligente de ordenação do mundo, relativo à ordem primeira de todas as coisas, Deus (God), no entendimento de John Finnis, precisa ser considerado como existente. 5 Portanto, a fim de melhor compreender a noção de religião apresentada por esse autor, deve-se pressupor que a ordem primeira de todas as coisas

\footnotetext{
5 "A explicação de sua existência pode apenas ser esta: que o estado de coisas causado sem causa incluí, como um pré-requisito para sua existência, um estado de coisas que existe devido ao que é, ou seja, devido ao fato de ser o que é. Será conveniente rotular esse último estado de coisas como D. No caso de todos os estados de coisas exceto D, podemos descrever o estado de coisas, afirmar o que ele é, sem saber que ele é (isto é, sem saber se é um estado de coisas existente). Mas, sobre D o argumento exige que afirmemos que o que é consiste em tudo que é exigido para que exista. Então, embora o argumento não nos forneça, a mais do que isso, uma melhor descrição sobre esse estado de coisas, sobre o que é, ainda assim, o argumento requer de nós a afirmação de que reconhecemos que D existe. Por tudo o que o argumento mostra, com necessidade racional (não lógica), é que se qualquer estado de coisas, que pode não existir, existe, então D deve existir; sem isso, nenhum estado de coisas que pode não existir poderia existir. Mas algum estado de coisas, que pode não existir, acontece que existe (por exemplo, o leitor lendo esta sentença). Então D deve (isso não é uma necessidade lógica) existir" (FINNIS, 2011a, p. 386-387, tradução nossa).
} 
exista e que, em seu pensamento é considerado Deus. Somente assim será possivel compreender os princípios éticos e políticos existentes, bem como as virtudes analisadas em suas obras.

Isso, pois os princípios objetivos da razoabilidade prática, quando pensados de maneira a excluir a existência dessa realidade, abrangem apenas o bem intrinsecamente existente no ser humano, ao qual se busca pelo próprio bem em si. Contudo, quando é identificada a presença desse ato criador, o bem da razoabilidade prática se constitui ainda em um bem munido de autoridade que busca se assimilar e se aderir a esse ato a fim de atingir ao florescimento humano.

Platão e Aristóteles não utilizam a existência de Deus ou de deuses como um argumento para justificar suas alegações de que existem normas objetivas do florescimento humano e principios da razoabilidade humana. Mas, os seus argumentos para justificar essa alegação, e sua reflexão acerca da natureza, objetiva, e fonte desses (e todos esses tipos de) argumentos, os levou a afirmar que há uma fonte transcendente de ser (isto é, de entidades e estados de coisas, e de sua existência) e, em particular, de nossa capacidade e desejo de compreender o ser (ou natureza) e suas diversas formas de bem. Então, ao perceber a natureza de alguém, no que concerne ao seu florescimento (eudaimonia), e (o que é a mesma coisa a partir de outro aspecto) em reconhecer a autoridade da razoabilidade prática, seus princípios, e seus requisitos, pode-se assim responder ao impulso divin e reconhecer a maestria de Deus (FINNIS, 2011a, p. 396, tradução nossa).

Logo, o bem humano básico da religião, para ser assim definido, precisa necessariamente ser precedido da ponderação sobre a existência dessa realidade criadora, já que consiste exatamente no questionamento e na harmonia com o transcendente. ${ }^{6}$ Assim, ao identificar esse aspecto racional inerente ao ser humano, Finnis destacou a característica pública de sua revelação, pois verificou que, ao ser revelada ao indivíduo essa realidade do ato criador, ele se percebe atraido a praticar uma conduta ética em relação a esse ato que o leva a buscar o bem comum da sociedade.?

\begin{abstract}
Em outras palavras, trazemos ao nosso exame da pregação e avaliação de seus professores e testemunhas, a nossa compreensão prévia do bem humano, uma compreensão que se insere, como argumentei, na raiz de nossa razão natural. E usamos isso como um critério para julgar, por nós mesmos, a autenticidade. a origem divina, do que está sendo proposto e exibido para nós. No entanto, por sua vez, a pregação, a testemunha e a vida exemplar dos professores podem e costumam mudar nossa prévia compreensão moral, aprimorando-a e corrigindo-a. Há, nessa medida, uma reciprocidade e um certo tipo de interdependência epistêmica da razão natural e da revelação pública divina, uma reciprocidade ou interdependência que se encaminha para uma espécie de equilíbrio reflexivo (como diria Rawls) (FINNIS, 2011b, p. 48, tradução nossa).
\end{abstract}

John Finnis entende, dessa maneira, ser essencial o equilibrio entre a razão natural e a revelação divina pública para o alcance do florescimento humano de cada um dos individuos inseridos na sociedade, que consiste nesse bem comum. Ao pensar no florescimento humano, ele percebe que não é possivel o alcance desse fim isoladamente da própria comunidade na qual o indivíduo se insere. Por isso, cada um dos bens humanos, inclusive a religião, direcionam as pessoas para uma efetiva cooperação humana, em cumprimento de princípios morais mestres, conforme se extrai da coletânea de artigos sobre religião organizada por Finnis:
Ainda assim, cada um dos bens básicos é um aspecto da realização ou do florescimento humano, e cada um é um bem, seja quem for, a pessoa humana na quail ele é ou pode ser instanciado. Assim, a razão compreende ainda mais a noção de uma satisfação humana inte- gral, isto é, a satisfação de todas as pessoas e comunidades humanas em todos os bens básicos. Essa noção não significa um novo bem básico ou razão para ação, e não aponta para uma meta alcançável pelo planejamento e cooperação humanos. Mas expressa o objeto (ou assunto) da diretividade combinada de todos os bens humanos básicos considerados

\footnotetext{
6 "As suposições que estou fazendo ou postulando nessa seção poderiam nos autorizar a dizer que Deus é um valor irrestrito, 'absoluto' e que a harmonia com Deus ('religião') é um valor humano básico. Elas não poderiam nos autorizar a dizer que religião é um valor mais básico do que qualquer um dos outros valores humanos básicos, de forma que 'pelo bem da religião' alguém pode corretamente escolher diretamente contra qualquer um desses outros valores ou ignorar qualquer um dos outros requisitos da razoabilidade prática" (FINNIS, 2011a, p. 410, tradução nossa).

"Então, a questão na essência de minhas reflexões é o status da revelação pública na razão pública. Revelação da natureza e intenções de Deus para nós é 'pública', no sentido focal, quando é fornecida na pregação pública atestada por sinais ou milagres tais como a ressurreição, ou senão a cura inexplicável, cumprimento de profecias, e assim por diante. Mas a força probatória desses é imensuravelmente reforçada por, talvez até dependente, do fato adicional de que o ensinamento à cuja autenticidade eles devem atestar, um ensinamento por meio da palavra e ação, é em si moralmente atrativo" (FINNIS, 2011b, p. 47-48, tradução nossa)
} 
em conjunto. O bem da razoabilidade prática, que Aristóteles denominou phronēsis e Aquino prudentia (com o seu objeto, o "bem da razoabilidade prática" [bonum rationis]), orienta-nos a aceitar a diretividade integral de todos os primeiros principios práticos, e a não permitir que emoções e sentimentos sub-racionais venham a impedi-lo ou desviá-lo. E essa diretividade integral dos primeiros principios da razão prática pode ser articulada em um princípio moral primário ou mestre: todos os desejos de devem ser compativeis com a realização humana integral (a realização de todas as pessoas humanas em todas as comunidades) - uma formulação altamente abstrata da declaração mais conhecida de que se deve amar e respeitar o próximo como a si mesmo. Princípios morais elevados, como a Regra de Ouro ou o principio que proíbe a imposição intencional de danos, são, então, especificações (eles mesmos, em muitos casos, ainda mais especificáveis) desse princípio moral primário ou mestre; eles identificam formas de disposição incompativeis com uma vontade constante e inflexivel de realização humana integral. Assim, a diretividade dos primeiros principios é racionalmente motivadora (contra Hume e Kant) e moralmente restritiva (assim como estimulante) (FINNIS, 2011b, p. 59, tradução nossa).

A religião definida dessa forma apresenta, assim como os demais bens humanos básicos, um caráter individual e outro público. Isso se justifica no sentido de que o ser humano em sua individualidade, em sua identidade, precisa exercer esses bens para o seu florescimento humano. De outro lado, como animal racional social, a pessoa humana se encontra inserida em uma sociedade e, portanto, precisa buscar a harmonia com os demais indivíduos nela também presentes. Logo, há um dualismo em cada um desses bens, exatamente devido à própria natureza do ser humano, por ser um animal político.

E esse dualismo necessita ser equilibrado para o alcance do florescimento humano e, assim, do bem comum. Uma das tentativas de se atingir esse equilibrio, conforme analisado por John Finnis, foi o documento do Concilio do Vaticano II (1962-1965) sobre a liberdade religiosa - Dignitatis Humanae (1965), o qual será estudado a seguir.

\section{A declaração sobre a liberdade religiosa Dignitatis Humanae e o pensamento de John Finnis}

Esse dualismo acima mencionado requer um "equilibrio reflexivo", conforme denominado por
John Finnis (2011b, p. 49), entre a razão natural e a revelação divina pública. Certo equilibrio necessita ser desenvolvido na vida daquele que crê em determinado ato criador de todas coisas (Deus ou deuses, dependendo da religião), bem como no ensinamento da própria comunidade estabelecida com a finalidade de sustentar a revelação histórica durante a história. Ausente esse equilibrio, a sociedade em si não consegue atingir o bem comum, uma vez que, sujeito aos ensinamentos e doutrinas de determinada religião revelada em uma comunidade especíica, o indivíduo deve buscar a harmonia entre esse aspecto público da revelação e a razão natural em si, que o faz questionar esse ser divino revelado.

Isso ocorre, mesmo em relação ao indivíduo que opta por não crer, pois ele se insere em uma comunidade específica sujeita a uma revelação pública cujos ensinamentos e doutrinas são desenvolvidos no decorrer da história da religião revelada. Caberá ao referido indivíduo, para alcançar o seu florescimento humano e o bem comum, buscar a harmonia, o equilibrio reflexivo da sua própria razão natural de não crer com essa religião revelada publicamente.

Como exemplo do desenvolvimento desse equilibrio reflexivo, John Finnis cita a "Declaração sobre a Liberdade Religiosa do Concilio do Vaticano II", de 1965. Nesse documento, percebe-se que a liberdade religiosa se fundamenta na dignidade da pessoa humana, no sentido de que todas as pessoas possuem direitos, como indivíduos e grupos, de não serem coagidos pelo Estado a tanto realizar quanto a não realizar atos religiosos.

De harmonia com própria dignidade, todos os homens, que são pessoas dotadas de razão e de vontade livre e por isso mesmo com responsabilidade pessoal, são levados pela própria natureza e também moralmente a procurar a verdade, antes de mais a que diz respeito à religião. Têm também a obrigação de aderir à verdade conhecida e de ordenar toda a sua vida segundo as suas exigências. [...] O direito à liberdade religiosa não se funda, pois, na disposição subjetiva da pessoa, mas na sua própria natureza. Por esta razão, o direito a esta imunidade permanece ainda naqueles que não satisfazem à obrigação de buscar e aderir à verdade; e, desde que se guarde a justa ordem pública, o seu exercício não pode ser impedido (CONCÍLIO VATICANO II - Dignitatis Humanae, 1965, n. 2). 
Há, entretanto, diante da necessidade de proteção dos direitos de todos, bem como da manutenção da paz e da moralidade pública, limitações a essa liberdade no que tange a imposições da ordem pública (FINNIS, 2011b, p. 49). ${ }^{8}$ Esse direito vislumbrado na Declaração Universal dos Direitos Humanos (1948) e, na Dignitatis Humanae (1965). impõe a todos uma responsabilidade reciproca, no sentido de que as outras pessoas, associações de pessoas e até o Estado, devem prestar respeito a essa liberdade.

Portanto, evidente é a relevância desse bem humano, por se tratar de uma das liberdades individuais e públicas inerentes ao ser humano que concede razão prática à conduta de cada pessoa. Nesse sentido, Finnis, no debate mencionado acerca da universalidade da liberdade religiosa, ao deparar-se com o questionamento sobre a existência de princípios fundamentais da liberdade religiosa universalmente aplicáveis, respondeu à questão positivamente:

No que tange à pergunta de quais princípios fundamentais da liberdade religiosa, se houver, são universalmente aplicáveis: Não apenas são esses princípios aplicáveis no decorrer de toda a diversidade das culturas e religiões do mundo, mas são aplicáveis mesmo no interior de diversas sociedades e experiências do Ocidente. Atrevo-me a dizer que o principio fundamental é que todos têm o direito natural ou humano de não serem coagidos no que consiste em buscar a verdade sobre questões religiosas, isto é, sobre assuntos relacionados à questão de saber se existe uma fonte transcendente do cosmos. Essas questões religiosas incluem não apenas a realização da pergunta e a resposta da pergunta, mas também colocar em prática resultados dessa busca, por exemplo, por proclamação e adoração, incluindo a proclamação pública e a adoração. Este é um direito cujo correlato vinculado é o dever de outras pessoas e grupos, incluindo o governo, de não se envolver em tal coerção com a intenção de restringir tal busca ou sem razão suficiente para proibir atividades que tenham impacto público. Há razão suficiente para a coerção tão somente quando a intenção é proibir ou restringir atividades na medida necessária para preservar a ordem pública, ou seja, os direitos de outros, incluindo seu direito à liberdade religiosa, à paz pública e à moralidade pública, incluindo apenas a ordem constitucional no interior da categoria de moralidade pública (FINNIS et al., 2011, p. 22).

O fundamento ético que sustenta o direito à liberdade religiosa, segundo Finnis, é exatamente "a dignidade humana inerente a cada pessoa que a capacita a buscar e a encontrar a verdade sobre as origens e os fins cósmicos e humanos" (FINNIS et al., p. 23). Nesse sentido, o Concilio Vaticano II, em seu documento Dignitatis Humanae (1965), discorreu sobre a dignidade humana inerente a cada pessoa de maneira a reconhecer que é precisamente essa dignidade que atribui a todos o direito à liberdade religiosa, sendo assim, ao mesmo tempo, imperativo a todos os outros individuos e grupos, incluindo o Estado, o seu respeito e o seu incentivo.

\begin{abstract}
Este Concilio Vaticano declara que a pessoa humana tem direito à liberdade religiosa. Esta liberdade consiste no seguinte: todos os homens devem estar livres de coação, quer por parte dos individuos, quer dos grupos sociais ou qualquer autoridade humana; e de tal modo que, em matéria religiosa, ninguém seja forçado a agir contra a própria consciência, nem impedido de proceder segunda a mesma, em privado e em público, só ou associado com outros, dentro dos devidos limites. Declara, além disso, que o direito à liberdade religiosa se funda realmente na própria dignidade da pessoa humana, como a palavra revelada de Deus e a própria razão a dão a conhecer. Este direito da pessoa humana à liberdade religiosa na ordem jurídica da sociedade deve ser de tal modo reconhecido que se torne um direito civil (CONCÍLIO VATICANO II. Dignitatis Humanae, n. 2).
\end{abstract}

A conduta do ser humano, quando respeitada essa liberdade religiosa, não o isola em si mesmo, mas permite com que ele se relacione com os outros, na medida em que deve agir em respeito à liberdade de cada um de crer ou não no mesmo conjunto de dogmas que ele o faz. Mas, ressalta-se aqui que, anteriormente a

\footnotetext{
8 "Um bom exemplo sobre esse processo de desenvolvimento do equilibrio reflexivo foi providenciado pela Declaração do Concilio do Vaticano II sobre a Liberdade Religiosa (1965). Este documento, que compensa seu estudo, identifica alguns dos mais sólidos e estáveis fundamentos da "esfera pública" (e muito mais). Frequentemente vai pelas duas primeiras palavras do seu texto latino, Dignitatis Humanae - sobre a dignidade da pessoa humana. O seu ensinamento principal pode ser apresentado brevemente. Todas as pessoas possuem o direito, como indivíduos, e como grupos, a não serem coagidos pelo governo, nem a praticar ou não praticar atos religiosos. Todas as pessoas possuem esse direito - de fato, até mesmo aqueles indivíduos ou grupos que formaram as suas próprias crenças religiosas sem o devido cuidado com a verdade. Somente será limitado pela necessidade da ordem pública, ou seja, pela necessidade de proteger os direitos dos outros, e defender a paz pública e a moralidade pública" (FINNIS, 2011b, p. 49, tradução nossa).
} 
esses dogmas atribuídos a uma religião institucionalizada especifica, existe, de acordo com o pensamento de John Finnis, Aristóteles e Tomás de Aquino, princípios práticos mestres da razão, tais como a dignidade da pessoa humana, que motivam racionalmente o agir de cada um, independentemente de suas crenças.

A Declaração sobre Liberdade Religiosa, conforme se depreende do trecho abaixo transcrito, enfatiza que nenhum individuo pode ser coagido a seguir uma determinada fé contra a sua vontade:

Um dos principais ensinamentos da doutrina católica, contido na palavra de Deus e constantemente pregado pelos santos Padres (8) é aquele que diz que o homem deve responder voluntariamente a Deus com a fé, e que, por isso, ninguém deve ser forçado a abraçar a fé contra vontade (9). Com efeito, o ato de fé é, por sua própria natureza, voluntário, já que o homem, remido por Cristo Salvador e chamado à adopção filial por Jesus Cristo (10), não pode aderir a Deus que Se revela a não ser que. atraido pelo Pai (11), preste ao Senhor o obséquio racional e livre da fé. Concorda, portanto, plenamente com a índole da fé que em matéria religiosa se exclua qualquer espécie de coação humana. E por isso o regime da liberdade religiosa contribui muito para promover aquele estado de coisas em que os homens podem sem impedimento ser convidados à fé cristã. abraçá-la livremente e confessá-la por obras em toda a sua vida (CONCÍLIO VATICANO II. Dignitatis Humanae, n. 4).

Nesse diapasão, John Finnis compreende que a coação de qualquer pessoa a seguir uma determinada fé, mesmo em prol da verdade religiosa, consiste em oposição à própria natureza humana. Qualquer imposição ou cerceamento de manifestação de uma fé, seja ela qual for, é contrário ao florescimento humano das pessoas em um de seus aspectos mais fundamentais, o qual trata da adesão e do molde integral de cada indivíduo a Deus. Em suas palavras:

O principal argumento justificador da razão natural é o seguinte: tão importante é para cada ser humano buscar, encontrar e viver de acordo com a verdade sobre Deus e o homem - a verdade religiosa - que, uma vez que impede, distorce ou tende a tornar inautêntica a busca da verdade religiosa, a coerção é má. O mal cometido [pela pessoa] é uma transgressão da pessoa cuja busca pela verdade, se não houvesse pressão coercitiva para conformá-la, poderia ter sido autêntica e centrada na verdade (sobre as coisas mais importantes), pelo menos como uma aspiração, ideal ou objetivo. Assim, essa pessoa (e, portanto, qualquer pessoa) tem o direito (reivindicação-de-direito) correlativo ao dever do governo de não cometer esse erro (FINNIS, 2011b, p. 49, tradução nossa). ${ }^{9}$

Ao ser questionado acerca do direito da liberdade religiosa mencionado na Dignitatis Humanae, no já citado Religious Freedom Project (Projeto sobre a Liberdade Religiosa), realizado pela Universidade de Georgetown, Finnis afirmou o seguinte:

\begin{abstract}
Existe um direito natural ou humano relativo à liberdade religiosa que é inerentemente universal, isto é, deve ser reconhecido por qualquer sociedade, mesmo aquelas cujo desenvolvimento cultural ainda não permitiu aos membros da sociedade reconhecer tal categoria de relações humanas como um direito humano natural. Este direito deve ser reconhecido mesmo por aquelas sociedades cuja cultura nega a verdade acerca de tais categorias ou a inclusão da liberdade religiosa inserida na categoria de direitos humanos (FINNIS et al., p. 22, tradução nossa).
\end{abstract}

Portanto, a liberdade religiosa de não ser coagido a seguir ou a não seguir uma determinada religião deve ser respeitada, a fim de permitir a cada ser humano o seu florescimento humano. Isso pois, somente lhe será possivel desabrochar quando livremente e autenticamente buscar a verdade sobre Deus e o homem, conforme mencionado. Iremos abordar então, no próximo tópico, exatamente a necessidade da proteção deste bem humano.

\section{A necessidade de proteção do bem humano básico da religião no espaço público contemporâneo}

Dessa forma, pode-se concluir, pelo exposto, que o florescimento humano dos indivíduos como seres sociais e racionais que são, exige a preser-

\footnotetext{
9 Do original: The principal justifying argument from natural reason is this: so important is it for each human being to seek, find, and live according to the truth about God and man - religious truth - that coercion, since it prevents, distorts, or tends to render inauthentic that search for religious truth, is wrongful. The wrong done is a wronging of the person whose search for truth, had there been no coercive pressure to conform, might have been authentic and centred on truth (about the most important things) at least as an aspiration, ideal, or goal. So that person (and thus any person) has the right (claim-right) correlative to the government's duty not to commit that wrong (FINNIS, John M. Religion and Public Reasons: Collected Essays Volume V. 2011b, p. 49).
} 
vação do bem humano da religião, assim como de todos os demais. Contudo, ao vislumbrarmos o cenário brasileiro e internacional, é possivel destacar diversas circunstâncias de desrespeito a esse bem no espaço público.

Um exemplo disso foi a decisão do Superior Tribunal Federal (STF) em 29 de maio de 2008 , que julgou improcedente a Ação Direta de Inconstitucionalidade (ADI 3510) proposta pela Procuradoria-Geral da República contra dispositivos da Lei de Biossegurança - Lei n. ${ }^{\circ}$ 11.105/05. Essa ação visou contestar a disposição contida no artigo $5 .^{\circ}$ dessa Lei, a qual versa sobre a utilização de células-tronco de embriões humanos em pesquisas e terapias. Isso porque a Procuradoria-Geral pugnou pela inconstitucionalidade desse artigo e de seus parágrafos, sob o fundamento de que não há previsão legal para tal utilização e, ainda mais, que a lei, ao permitir essa prática, afronta dispositivos constitucionais relativos ao direito à vida e à dignidade da pessoa humana.

No decorrer do processo perante o STF, a Conferência Nacional dos Bispos do Brasil (CNBB) - que participou do processo como amicus curiae - defendeu uma posição contrária à utilização das células-tronco, de maneira a postular a inconstitucionalidade dos dispositivos mencionados da Lei de Biossegurança. Contudo, o STF rejeitou a oposição da CNBB, por entender a atuação da Conferência como intromissão da Igreja e da religião em assuntos públicos de um Estado laico. Isso se pode extrair do voto do Ministro Celso de Mello, sob o argumento de visar à defesa de uma suposta liberdade religiosa, senão vejamos:

Nesse contexto, e considerado o delineamento constitucional da matéria em nosso sistema juridico, impõe-se, como elemento viabilizador da liberdade religiosa, a separação institucional entre Estado e Igreja, a significar, portanto, que, no Estado laico, como o é o Estado brasileiro, haverá, sempre, uma clara e precisa demarcação de domínios próprios de atuação e de incidência do poder civil (ou secular) e do poder religioso (ou espiritual), de tal modo que a escolha, ou não, de uma fé religiosa revele-se questão de ordem estritamente privada, vedada, no ponto, qualquer interferência estatal, proibido, ainda, ao Estado, o exercicio de sua atividade com apoio em princípios teológicos ou em razões de ordem confessional ou, ainda, em artigos de fé, sendo irrelevante - em face da

\begin{abstract}
exigência constitucional de laicidade do Estado - que se trate de dogmas consagrados por determinada religião considerada hegemônica no meio social, sob pena de concepções de certa denominação religiosa transformarem-se, inconstitucionalmente, em critério definidor das decisões estatais e da formulação e execução de politicas governamentais. O fato irrecusável é que, nesta República laica, fundada em bases democráticas, o Direito não se submete à religião, e as autoridades incumbidas de aplicá-lo devem despojar-se de pré-compreensões em matéria confessional, em ordem a não fazer repercutir, sobre o processo de poder, quando no exercício de suas funções (qualquer que seja o dominio de sua incidência), as suas próprias convicções religiosas (ADI 3510).
\end{abstract}

Assim, sob a alegação de proteger a liberdade religiosa, o STF rejeitou os argumentos prestados pela CNBB, por compreender conforme depreende-se do trecho acima transcrito, que as decisões jurídicas não podem ser submetidas à religião. Assim, as autoridades judiciárias que possuem como responsabilidade aplicar o Direito em casos concretos apresentados ao Poder Judiciário de cada Estado, devem se deter a fazê-lo de maneira neutra, isenta de quaisquer convicções religiosas próprias.

Dessa forma, o que se percebeu não foi um respeito à liberdade religiosa, mas uma prévia consideração de que os pontos destacados pelo advogado da CNBB, Ives Gandra Martins, eram meramente de cunho religioso. Contudo, ao argumentar em defesa da posição da Conferência nesse caso, Ives Gandra apresentou como fundamentos, princípios científicos e jurídicos, não apresentando posições meramente religiosas, mas sim argumentos em defesa da dignidade humana.

Esse é apenas um dos diversos exemplos nos quais, em prol de uma alegada liberdade religiosa, rejeita-se qualquer argumento de entes religiosos no âmbito público, sob o fundamento de ser o Brasil um Estado laico. Portanto, conforme analisado anteriormente, sob a ótica do pensamento de John Finnis, a liberdade religiosa não consiste em rejeitar quaisquer posições como a da CNBB, simplesmente pelo fato de as considerar religiosas. Ao contrário, ao discorrer sobre a liberdade religiosa, principalmente quando da análise do documento Dignitatis Humanae, Finnis entende que decisões como a do STF oprimem o bem 
humano básico da religião, de forma a impedir o florescimento humano de cada cidadão. Conforme suas palavras a Dignitatis Humanae, "está dedicada ao direito de ser livre da coerção social, incluindo legal, em assuntos de crença e prática religiosa, dentro dos limites da ordem pública: que é, a paz pública, respeito pelo direito justo dos outros, e por uma boa moralidade pública" (FINNIS, 2016, p. 4, tradução nossa). Então, o principal intuito dessa declaração do Concilio do Vaticano II é proteger os cidadãos de qualquer ato que ofenda as suas crenças religiosas particulares, sejam elas quais forem. Essa proteção também é atribuída em relação àqueles que não creem na fé cristã católica, sendo impedida qualquer imposição coativa a eles, conforme já mencionado anteriormente.

\section{Considerações finais}

Cabe ressaltar os apontamentos de Simões e Fadel acerca do pensamento de John Finnis sobre religião:

A religião é um valor fundamental em John Finnis, na medida em que o homem se expressa, também, através da religião. Quando o referido autor se refere à religião, ele não se refere a uma religião especifica, nem mesmo remete a uma religião única, pelo contrário, afirma que o aspecto religioso é um aspecto necessário, historicamente verificado nas manifestações humanas, inclusive a manifestação antiteísta, ou seja, é possivel que o indivíduo não queira professar nenhuma religião ou, mesmo, não crer em Deus. A relação que Finnis traça é da religião estar interligada ao sentido de buscar as origens de sua existência, "uma origem transcendente da ordem universal das coisas". Nesse sentido, esse direito de "não crer", também, é uma manifestação ligada ao item religião em Finnis, isto porque pelo simples fato de, em uma determinada sociedade, ter-se a condição não religiosa, esta valida à existência da condição religiosa. Outrossim, se existe a religião como uma manifestação social, o individuo pode simplesmente não a querer para sua vida (FADEL; SIMÕES, 2017, p. 584-585).

Ainda, diante dessa compreensão, os autores citados continuam a discorrer sobre o entendimento de John Finnis no que concerne à prática da religião como bem humano nas sociedades e a necessidade de sua proteção:
Contudo, se a religião fosse proibida, se o Estado retirasse a possibilidade de manifestação religiosa, não haveria a possibilidade de exercer a não religião como um direito, pois a mesma seria uma imposição. Portanto, há uma relação de dualidade: o direito de não crer só pode ser um direito, se a manifestação religiosa também o for, elas são faces de uma realidade e utilizando a mesma regra de validação de Finnis. Dessa maneira, observa-se que toda a sociedade humana, ao longo da história, não há nenhuma delas em que não exista uma forma religiosa de expressão da cultura, expressão de entendimento sobre o que os seres humanos são e qual o seu sentido no mundo, se a religião não é acidental, se ela é universal, porque ela é constitutiva do que os individuos são, de alguma maneira, estes se compreendem a partir dela, não há como sustentar que isso seja secundário (FADEL; SIMÕES, 2017, p. 585).

Nesse sentido, o Estado possui como um de seus deveres proteger e incentivar a liberdade religiosa, de forma que não deve permitir a qualquer uma de suas autoridades a supressão, restrição desse direito, mas sim o respeito à liberdade de cada pessoa de manifestar a sua religião, seja ela qual for. Então, a religião como bem humano fundamental básico precisa ser protegida, e, para isso, a liberdade religiosa deve ser compreendida de maneira clara, não sendo possivel aplicá-la de forma a suprimir qualquer pensamento religioso. Caso fosse suprimido qualquer pensamento religioso, somente por compreendê-lo como religioso, estaria assim impedindo a busca livre e autêntica da pessoa em questão, de buscar racionalmente por si mesma a verdade sobre o cosmos e sobre sua própria vida.

Um Estado que suprima a possibilidade da reli-
gião falha, imensuravelmente, pois transforma
o direito dos individuos de não se manifestar
religiosamente em dever e, por consequência,
nega que religião compõe a mais importan-
te manifestação de uma cultura, como uma
verdadeira identificação histórica. Portanto, a
liberdade religiosa é condicionante do próprio
ser humano. Assim, nenhum governo, nenhuma
sociedade teria o direito de suprimi-la (FADEL;
SIMÕES, 2017, p. 585).

Portanto, diante da dualidade relativa aos bens humanos básicos (privado e público), a liberdade religiosa protegida na Dignitatis Humanae, bem como em diversas outras normas internacionais e de Direito interno de vários Estados (sendo alguns 
aqui citados), confere a cada ser humano a responsabilidade de permitir aos outros o florescimento humano. Isto é, cada pessoa em sua individualidade é responsável pelo florescimento humano das pessoas ao seu redor. Portanto, a liberdade religiosa é um direito que deve ser protegido por todos, de maneira que deve ser evitada a sua supressão por qualquer individuo, coletividade ou Estado.

Por fim, de acordo com o entendimento inovador de John Finnis acerca da existência de bens humanos fundamentais básicos que proporcionam o florescimento de cada pessoa, cabe a cada Estado de Direito zelar pela proteção e pela fomentação de cada um desses bens. Para tanto, deve-se visar sempre à proteção do bem humano da religião, com o cumprimento do direito à liberdade religiosa, que é um dos aspectos do florescimento humano, e que proporciona o bem comum de toda a sociedade.

\section{Referências}

SUPERIOR TRIBUNAL FEDERAL. ADI 3510. Relator(a): Min. AYRES BRITTO, Tribunal Pleno, julgado em 29/05/2008, DJe-096 DIVULG 27-05-2010 PUBLIC 28-05-2010 EMENT VOL-02403-01 PP-00134 RTJ VOL00214-01 PP-00043. Disponivel em: http://www.stf. jus.br/portal/geral/verPdfPaginado.asp?id $=611723 \&-$ tipo $=$ AC\&descricao $=$ Inteiro $\% 20$ Teor $\% 20$ ADI $\% 20 / \% 20$ 3510. Acesso em: 04 dez. 2018.

ARISTÓTELES. Metafisica. Tradução, textos adicionais e notas Edson Bini. Bauru. São Paulo: Edipro, 2006.

BIELEFELDT, Heiner. Freedom of Religion or Belief- A Human Right under Pressure. Oxford Journal of Law and Religion, [S. l.], v. 1, n. 1, p. 15-35, 2012. doi:10.1093/ ojlr/rwro18 Disponivel em: https://academic.oup.com/ ojlr/search-results?f_Authors=Heiner+Bielefeldt. Acesso em: 30 ago. 2020

BRASIL. [Constituição (1988)]. Constituição da República Federativa do Brasil de 1988. Disponivel em: http://Www. planalto.gov.br/ccivil_03/constituicao/ConstituicaoCompilado.htm. Acesso em: 29 ago. 2020.

CONCÍLIO VATICANO II. Dignitatis Humanae. Petrópolis: Vozes, 1966.

FADEL, Anna Laura Maneschy; SIMÕES, Sandro Alex Souza. O uso de símbolos religiosos nos espaços públicos e o mito da neutralidade do secularismo nos Estados modernos: uma análise da religião como um bem humano básico, à luz da teoria de John Finnis. Revista da Faculdade de Direito da Universidade de Minas Gerais, Belo Horizonte, n. 71, p. 553-591, jul./dez. 2017. Disponivel em: https://www.direito.ufmg.br/revista/index.php/revista/ article/view/1893/1795. Acesso em 04 de dezembro de 2018. https://doi.org/10.12818/P.0304-2340.2017V71P553.
FINNIS, John M. Natural Law and Natural Rights. 2. ed. Oxford University Press [1980], 2011a.

FINNIS, John M. Religion and Public Reasons: Collected Essays. Oxford University Press, 2011b. Volume V.

FINNIS, John M. Towards Vatican II's Centenary: Yournext fifty years. IS. l.], p.1-18, Fall 2016. Disponivel em: https://lawreview.avemarialaw.edu/wp-content/uploads/2019/06/ vXIV.Finnis.layout2.0426.pdf. Acesso em: 12 set. 2020.

FINNIS, John et al. The Universality of Religious Freedom and its Compatibility with Non-Western Cultures In: REPORT OF THE GEORGETOWN SYMPOSIUM ON WHAT'S SO SPECIAL ABOUT RELIGIOUS FREEDOM? Washington, Nov. 17, 2011, p. 22-29. Disponivel em: https://berkleycenter.georgetown.edu/publications/ what-s-so-special-about-religious-freedom. Acesso em 17 de dez. 2018.

ONU (Organização das Nações Unidas). Declaração dos Direitos Humanos [Brasil]. 2009. Disponivel em: https:// nacoesunidas.org/wp-content/uploads/2018/10/ DUDH.pdf. Acesso em: 29 ago. 2020.

ONU (Organização das Nações Unidas). Declaração Universal dos Direitos Humanos [Portugal]. Disponivel em: https://www.ohchr.org/EN/UDHR/Pages/Language. aspx? LanglD=por Acesso em: 29 ago. 2020

PORTELA, Paulo Henrique Gonçalves. Direito Internacional Público e Privado. 6. ed. Salvador: Juspodivm, 2014.

SOUZA, Elden Borges; PINHEIRO, Victor Sales. O Laicismo e a Teoria da lei natural, em Finnis: A Religião como bem humano básico. [S. l.], 2016a. p. 2-22. Disponível em: https://www.ojs.ufpi.br/index.php/raj/article/ view/5702. Acesso em: 26 jun. 2017.

SOUZA, Elden Borges; PINHEIRO, Victor Sales. A Fundamentação Ética dos Direitos Humanos em John Finnis, 2016b p. 65-83. Disponivel em: https://www.revistas. unijui.edu.br/index.php/direitoshumanosedemocracia/ article/view/5513. Acesso em: 26 jun. 2017. https://doi. org/10.21527/2317-5389.2016.7.65-83.

SUPREMO TRIBUNAL FEDERAL, Tribunal Pleno, MS 22.164/SP. Relator: Celso de Mello, Brasília, DF, 30.out. 95, DJ de 17.11.95, p. 39206. Disponivel em: http://redir. stf.jus.br/paginadorpub/paginador.jsp?docTP=AC\&doclD=85691. Acesso em: 10 set. 2020.

\section{Laura Souza Pires do Rio}

Mestre em Ciências da Religião pela Universidade Puc Minas. Possui graduação em Direito pela Faculdade Milton Campos. Tem experiência na área de Direito trabalhista e civel.

Endereço para correspondência

Laura Souza Pires do Rio

Alameda dos Madrigais, 330

Pasárgada, 3009-574

Nova Lima, MG, Brasil 